\title{
Desarrollo y territorio. Una visión desde los procesos de sojización del Cono Sur de América Latina 1
}

\author{
Development and territory. A view from the soy-ization of the Latin \\ American Southern Cone
}

\section{Mabel Manzanal}

\begin{abstract}
Universidad de Buenos Aires, Facultad de Filosofía y Letras, Programa de Estudios Regionales y Territoriales, Buenos Aires; CONICET, Universidad de Buenos Aires, Instituto de Geografía "Dr. Romualdo Ardissone", Buenos Aires, Argentina.
\end{abstract}

\section{PALABRAS CLAVE}

Desarrollo

Territorio

Políticas públicas

Sojización

\section{KEYWORDS}

Development

Territory

Public policies

Soy-ization

\section{RESUMEN}

En este artículo realizamos un análisis crítico sobre la relación entre desarrollo y territorio a partir del avance de la sojización en el Cono Sur latinoamericano. El trabajo se inicia con una periodización e interpretación respecto a las etapas en que la cuestión del desarrollo y el territorio se constituyó en política de estado. En este análisis se considera que la cuestión del desarrollo y del territorio y su presencia recurrente en la política pública tiene que ver con la construcción de hegemonía a través de la producción de un discurso, explicitado por medio de propuestas, opciones, acciones, e instrumentos dirigidos a enfrentar el problema social del desarrollo desigual (sea en relación a lo espacial, económico, social e incluso institucional). Desde esta interpretación se analiza la expansión de los commodities y la consolidación de un modelo de acumulación cada vez más concentrado y regresivo, que se traduce en una mayor y creciente desigualdad. Se trata de una concentración económica que beneficia a una minoría privilegiada mientras se avasallan los derechos de los sectores más desprotegidos y precarizados del ámbito rural y urbano. El trabajo pone en cuestión al contexto cultural hegemónico que logra que las actuales consecuencias de la producción del territorio y de valorización del capital (ligadas al extractivismo y a la reprimarización de las economías sudamericanas) se tornen lejanas e incomprensibles para la gran mayoría de la población, que desconoce, minimiza o desestima la profundización de la desigualdad y la marginación social, las consecuencias ambientales, políticas, económicas, sociales e institucionales -presentes y futuras- del avance de los commodities, la persecución, la opresión y la discriminación de los numerosos actores.

\section{ABSTRACT}

In this article we will realize a critical analysis about the relationship between development and territory from the advance of the soy-ization in the Latin-American Southern Cone. The work begins with a chronological framework and an interpretation of the stages in which the issue of development and territory became a state policy. In this analysis we consider that the issue of development and territory and its recurring presence in the public policy has to do with the construction of hegemony through the discourse production, explicit through proposals, options, actions and instruments aimed at dealing with the social problem of unequal development (regarding spacial, economical, social o even institutional matters). From this interpretation we analyze he commodity expansion and the consolidation of an accumulative model that is more concentrated and regressive, and which produces a grater and growing inequality. This is an economical concentration that benefits a privileged minority whereas the rights of the unprotected and precarious sectors of the rural and urban area are humiliated. This work questions the hegemonic cultural context which makes the current consequences of the territory production and the capital valuation (linked to the extractivism and the refocusing of the south-American economies) distant and incomprehensible for the majority of the population who ignore, minimize or disdain the deepening of the inequality and the social marginalization; the environmental political, economic, social and institutional consequences - nowadays or in the future - of the commodities advance; and the persecution, oppression and discrimination of the numerous parties. 


\section{Antecedentes}

En Argentina y América latina (AL), la relación entre política pública (PP) y territorio, vinculada a propuestas de desarrollo (sea nacional, regional, local, territorial u otros calificativos de sentido similar) tiene su origen en torno a la década de 1960. La incorporación del espacio como una variable expresamente considerada en la PP se evidencia en dos períodos bien diferenciados de la historia argentina y latinoamericana. El primero ocurre entre 1960 y 1975 (o 1980 según los países ${ }^{2}$ ) y coincide con la etapa en que las PP estaban dominadas por el modelo de sustitución de importaciones, el keynesianismo, el desarrollismo y la planificación del desarrollo nacional y regional.

En este período, el temor promovido desde Estados Unidos (durante la presidencia de John F. Kennedy) a que la expansión de la revolución cubana (1959) se extendiera hacia toda Latinoamérica fue el motor que llevó a la creación de la Alianza para el Progreso (cuya piedra fundacional se dio en la Conferencia de Punta del Este de agosto de 1961) $)^{\underline{3}}$.

De este modo, la revolución cubana junto con la guerra fría (presente desde la segunda postguerra -1945entre el mundo occidental y capitalista y el oriental y comunista) fueron los principales determinantes externos que impulsaron una atención especial a la problemática del "subdesarrollo" de AL y de sus diferencias regionales al interior de cada país, entre zonas más y menos subdesarrolladas y/o marginales.

El segundo período en que reaparece la cuestión del territorio y la política en consonancia asociada comienza entre 1995 y 2000 (el inicio varía según cada país) ${ }^{4}$. El año de inicio está vinculado con el momento en que comienzan a observarse más claramente, para la sociedad en su conjunto, los efectos negativos (desocupación, inflación, endeudamiento) del ajuste aplicado por el modelo neoliberal.

Entre estos dos períodos corre un lapso de aproximadamente 20 años (que varía según los países entre 1975 y 2000) en el que la cuestión regional y/o territorial perdió vigencia, estuvo ausente o tuvo escasa relevancia para las PP. Se trataba de un contexto discursivo en el que todo aquello que estuviera vinculado con pensar o planear de un modo particular el espacio, la región y/o el territorio carecía de legitimidad en razón de la nueva praxis cultural que buscaba la construcción y constitución de una nueva hegemonía $\underline{5}$. El neoliberalismo no fue sólo un programa de política económica, fue además, y muy especialmente, una propuesta de transformación cultural, en la que la represión, el ocultamiento y la desinformación se potenciaron para imponer el ajuste y sus consecuencias $\underline{6}$.

Aun a pesar de este contexto ideológico impuesto, hacia 1995 o 2000 empezaron a visibilizarse las dificultades sociales y económicas resultantes del ajuste macroeconómico, de las privatizaciones, de las desregulaciones y de la apertura al mercado externo. Entonces, junto con el surgimiento de diferentes formas de resistencia social (movilizaciones, paros) comenzaron a delinearse nuevas propuestas de PP, centradas en la promoción y divulgación de políticas de desarrollo endógeno, desarrollo local, desarrollo territorial. En este contexto, nuevamente se conforman PP asociadas al territorio, aunque bajo una forma nueva, de sustento neoclásico, que articulaba con el accionar de la población local.

Años después, a esta construcción conjunta, o coproducción de PP, entre el estado y la sociedad se la reconocerá como gobernanza, que indica la incorporación de los actores del mercado y de la sociedad civil al proceso de gobernar (antes dominado por los gobiernos y el estado). Es desde entonces que el territorio en sus diversas expresiones cobra nueva centralidad, hecho que se mantiene hasta el presente. 


\section{La desigualdad social y económica a nivel mundial}

De todos modos y a pesar de esta siempre reinventada "cuestión del desarrollo" (y de las diferentes PP que han pretendido históricamente atender el problema social resultante del desarrollo desigual) continuamos coexistiendo con el mismo problema en su versión siglo XXI. Valga con sólo observar el actual contexto mundial, regional y nacional de enormes desigualdades: mientras la economía mundial funciona al servicio del 1\% más rico, para el 10\% más pobre tan sólo queda convivir con el hambre, la escasez de alimentos y la pobreza en sus diferentes expresiones (Oxfam 2016, Credit Suisse 2015).

La realidad del presente nos indica que la distribución de la riqueza mundial y del crecimiento interanual de dicha riqueza es cada vez más desigual, por lo que se suceden situaciones éticamente inaceptables como que el crecimiento global de los ingresos acumulados entre 1988 y 2011 se distribuya del siguiente modo: 46\% a favor del 10\% más rico y apenas quede un $0.6 \%$ para el 10\% más pobre (OXFAM, 2016)

Desde luego que en Argentina y América Latina (AL) somos parte y contribuimos a la generación de estas desigualdades a través de variadas formas de producción de plusvalía y excedentes (como sucede con la notoria y acelerada expansión de la soja, la explotación de minerales e hidrocarburos, la especulación financiera e inmobiliaria).

Paralelamente, en Argentina y en los restantes países de AL y del resto del mundo viven mayorías sociales que padecen directamente la desigualdad: población desocupada, precarizada, excluida, pauperizada (que incluso alcanza a amplios sectores medios) que padece diferentes formas de restricción en sus condiciones de vida, especialmente quienes tienen limitadas oportunidades laborales, educacionales, sanitarias, habitacionales, de ingresos, por su inserción subordinada en los procesos productivos, políticos, institucionales y sociales.

Precisamente, es esta inserción subordinada de amplios sectores sociales una de las primeras cuestiones que deberían revertirse globalmente para modificar los parámetros de desigualdad que tienden a acrecentarse. Y es para ello que necesitamos transitar por el camino de un cambio cultural a través de una nueva pedagogía que incorpore la legitimidad de la resistencia social, del accionar colectivo, de la institucionalización y del fortalecimiento de organizaciones productivas, laborales y educacionales a favor de las mayorías marginadas. En estos ámbitos importa compenetrarnos y discutir respecto de las condiciones de desigualdad que resultan funcionales al modelo capitalista, repensando y accionando conjuntamente respecto a las posibilidades, limitaciones y viabilidad de otro tipo de crecimiento, distribución y consumo.

Desde los movimientos, las organizaciones y la población movilizada es posible gestionar políticamente el crecimiento instrumentando formas institucionales de carácter fiscal, reconocidas y aplicadas globalmente, y dirigidas a una distribución más equitativa entre los diferentes estratos y clases sociales. Sólo desde otro modelo de distribución de los ingresos y de los recursos es posible reducir significativamente la pobreza, la indigencia y consecuentemente la desigualdad. Desde luego que esto exige una gobernanza global, instrumentada por organismos internacionales de nuevo tipo (que desplace a los actuales organismos neoconservadores y dominados por la persistente hegemonía geopolítica de los Estados Unidos). Es esta otra gobernanza la que debemos promover.

Precisamente, cálculos realizados por estudiosos de estos temas muestran la posibilidad de que enormes masas de población dejen de ser pobres con tan sólo hacer algunas intervenciones de política pública (nacional y/o internacional) en la masa de crecimiento anual de la riqueza de los más ricos. Por ejemplo, a través del aumento de los salarios, la reducción de las brechas salariales con los grandes directivos de empresas, el control de la capacidad de influencia de las élites más poderosas, la regulación de los precios de los medicamentos a nivel mundial, la promoción de un sistema fiscal e impositivo más justo, equitativo y 
progresivo. Se estima que 200 millones de personas podrían dejar de ser pobres si los ingresos del 40\% más pobre aumentaran al mismo ritmo que la media en todos los países, o que la pobreza se podría reducir a la mitad si los ingresos del $40 \%$ más pobre de la población se incrementaran dos puntos porcentuales por encima de la media (OXFAM, 2016, p. 11).

Es inconcebible reconocer que una economía mundial que duplicó su producto (PBI) en los últimos 30 años (alcanzando los 78 mil millones de dólares en 2014), y su riqueza (267 mil millones de dólares en activos financieros y no financieros en 2015) en la mitad de aquel tiempo (los últimos 15 años), sea una economía excluyente y genere lo que, eufemísticamente, se podría llamar un desarrollo excluyente -en tanto los más pobres no participan de los beneficios del crecimiento de la riqueza que contribuyen a generar-. Por el contrario, son los más ricos (el 1\%) de la población mundial los que acaparan el $43 \%$ de la riqueza mientras el 80\% de la población sólo dispone del 6\% de la misma (OXFAM, 2016).

Se trata de contradictorias diferencias que también pueden observarse en los dos gráficos que siguen (Oxfam, 2016)

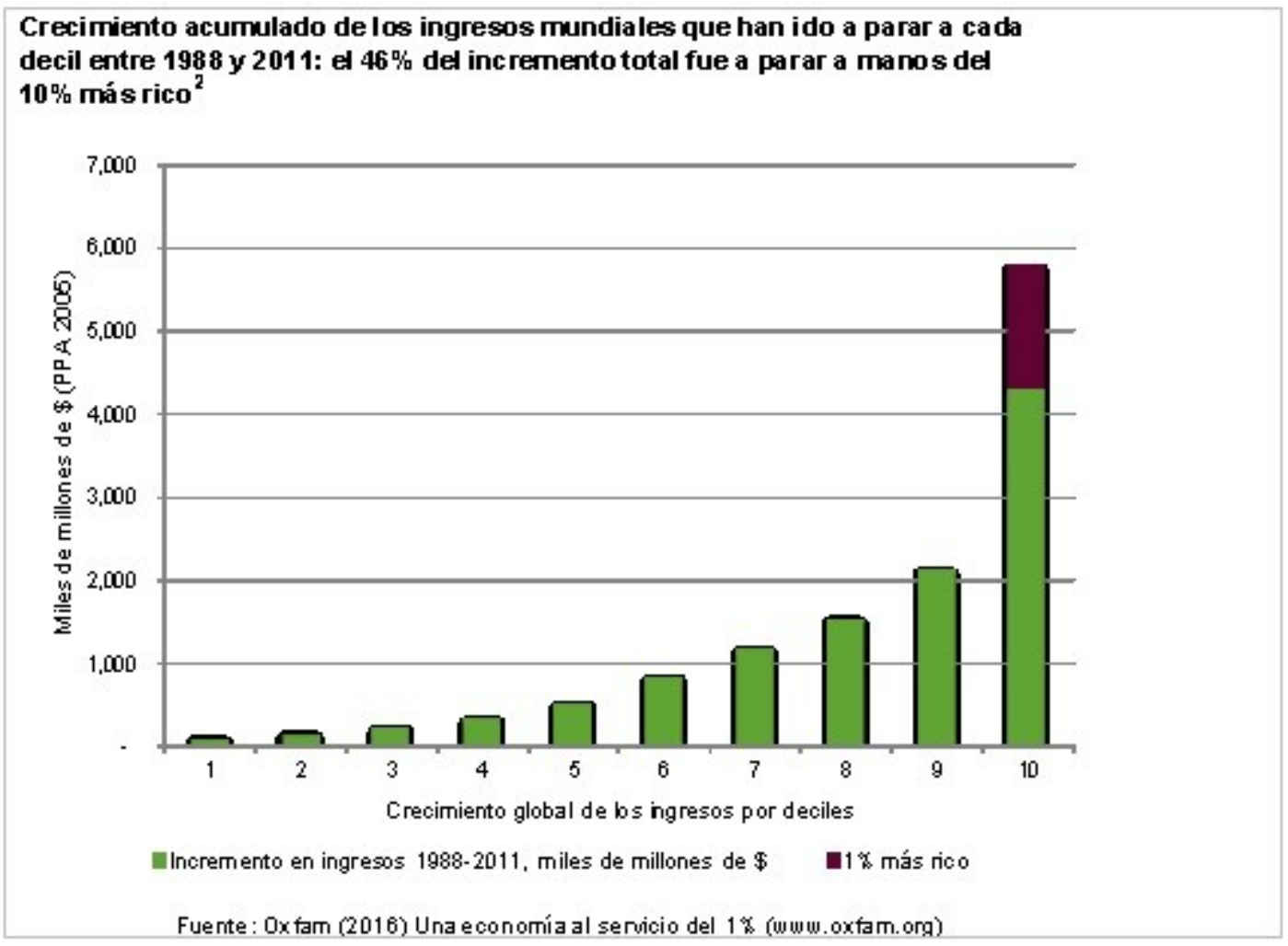




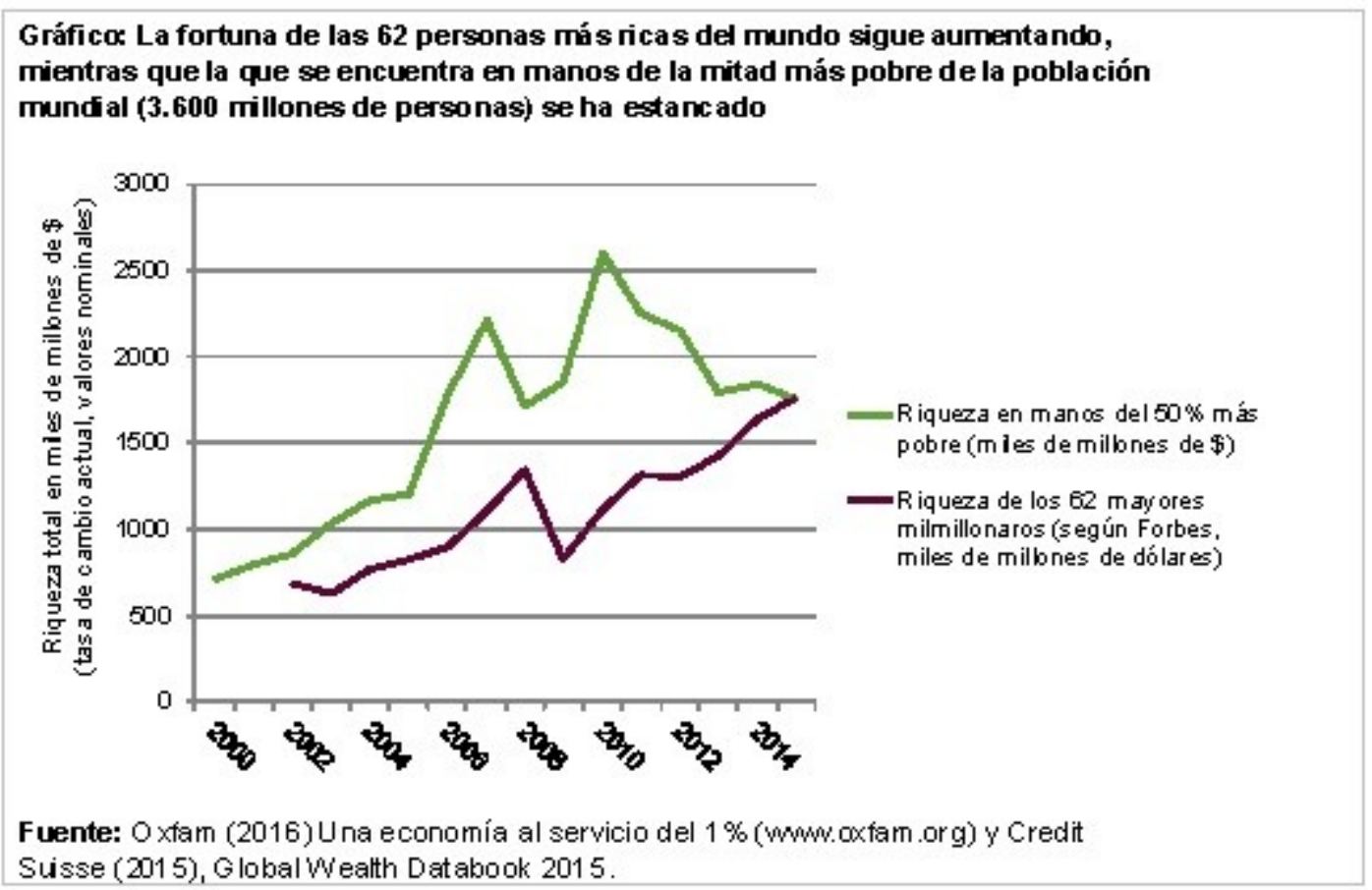

\section{Desarrollo y territorio en las políticas públicas de América Latina}

En AL no podemos desconocer que cualquier revisión histórica de los resultados de las PP de desarrollo indica que en medio siglo (desde 1960 a la actualidad -desde que se empezó a pensar el desarrollo y el espacio como parte constituyente del accionar político del estado) no se han podido superar los principales escollos que impiden la sustentabilidad del desarrollo. A pesar de la proliferación de políticas de desarrollo que desde entonces se han sucedido (desarrollistas, keynesianas, neoliberales, neoestructuralistas) no se logra revertir la persistencia del hambre, la pobreza, la desigualdad económica, social y de género; el desempleo y la precariedad laboral; los déficit habitacionales, educacionales, de salud, de saneamiento; la persecución y represión política contra quienes se oponen o diferencian de las prácticas hegemónicas -como los pueblos originarios, las comunidades campesinas, la población identificada con los derechos de género, de la diversidad sexual o con la problemática ambiental y el cambio climático-. Las restricciones estructurales no han logrado modificarse a pesar de múltiples y diversas "políticas de desarrollo" generadas y aplicadas durante los últimos 50 años (o incluso desde antes de que existieran formalmente como tales).

Múltiples calificativos recibieron estas "políticas de desarrollo" (nacional, regional, local, endógeno, territorial, sustentable, ambiental, humano, sostenible). Sin embargo, sólo transitoria y parcialmente algunas cuestiones (como el desempleo, la salud, la vivienda, el saneamiento) lograron mejorar con ciertos gobiernos (en general identificados con el "populismo"). Precisamente, corresponde detenerse y prestar atención a estos retrocesos para preguntarse: ¿por qué las mejoras parciales no lograron consolidarse y modificar su tendencia en forma permanente?

La respuesta está en la estructura y la cultura hegemónica que siempre vuelve sobre sus pasos y se consolida, con el apoyo de los sectores dominantes presentes en los gobiernos, en la sociedad, en las empresas, en los organismos multilaterales y en la banca de financiamiento nacional e internacional. Este es el verdadero problema del presente y del largo plazo de las mayorías sociales, condicionante de la sustentabilidad del desarrollo: la democracia se torna incompatible bajo el control corporativo multinacional ${ }^{7}$.

Es en este contexto que, junto al nuevo milenio, surge el paradigma que subraya la importancia del territorio 
y de la gestión territorial del desarrollo ${ }^{8}$. La noción de territorio que aparece, explícita o implícitamente, en estas PP no difiere demasiado de la tradicional visión naturalista propia del determinismo geográfico, en la que el "territorio" corresponde al ámbito donde los estados ejercen soberanía, o al "escenario" receptor de acciones, inversiones, construcciones, población.

Es hacia la primera década del segundo milenio cuando se empieza asociar al "territorio" con el accionar de actores y sujetos, y se diferencian particularidades entre distintos ámbitos espaciales. Entonces, desde las PP conocidas como de "desarrollo territorial” se asoció el territorio con la "atmósfera” particular y diferente de cada lugar o espacio. Sin embargo, desde nuestra perspectiva esta noción tampoco se aleja demasiado de las identificaciones previas.

El problema en todos los casos radica en que no se visualiza al territorio como poder. El territorio se disputa, en el territorio los actores ejercen territorialidad, su ejercicio de poder. Desde esta perspectiva el territorio es poder. Por el contrario, cuando se mitifica su naturaleza, un sinnúmero de determinantes en el accionar de las políticas y de los actores permanece oculto, sesgado, lo que impide pensar y delimitar el accionar político vinculado con las PP, con su formulación, diseño, intervención y gestión.

Todo lo anterior nos indica que deberíamos modificar el campo teórico-metodológico de interpretación (del desarrollo, del territorio, de la política y de las instituciones en general) y, consecuentemente, el campo empírico de investigación. Es muy importante tener presente que estamos operando con conceptospropuestas que son "construcciones sociales", es decir, construcciones en las que participan actores con distinta inserción territorial, social y de clase, con diferente integración a redes y a prácticas específicas de poder, con particulares territorialidades y escalas de acción (de lo mundial a lo local). Se trata de un contexto en el que importa tener presente: ¿cómo formular políticas de desarrollo sustentable si no reconocemos que buena parte de lo que sucede en los territorios puede obviar las regulaciones y controles del Estado-Nación y resultar directamente en “una localización de lo global”? (Sassen, 2007, p. 29).

Tampoco es posible pensar políticas de desarrollo sustentable con una cultura hegemónica que avala o se desinteresa de la desigualdad y de la subordinación social que lleva implícita.

Creemos que estas temáticas pueden visualizarse más claramente revisando lo que sucede en Argentina y en el Cono Sur con los procesos de reprimarización de las economías latinoamericanas. A través de ellos podremos descubrir más acabadamente ciertas realidades que parecen sistemáticamente ocultarse al conjunto de la población.

\section{- La desigualdad avanza impulsada por las nuevas modalidades de acumulación y las nuevas territorialidades}

En el contexto arriba descripto nos preguntamos (recordando las múltiples indagaciones de David Harvey sobre este tema): ¿Cuáles son las configuraciones territoriales que garantizan la sobrevivencia del capitalismo en el presente? ¿Cuáles son las nuevas geografías que valorizan al capital? ¿Por qué o qué modalidades de acumulación hacen que este capitalismo sea cada vez más desigual?

Actualmente el capitalismo se expande, acumula y concentra a través de procesos productivos y especulativos ligados a la urbanización y suburbanizacion, la expansión de commodities, los agronegocios, la difusión de formas extractivistas de producción.

Se trata de nuevas geografías de valoración del capital asociadas con la financiarización de la economía, la producción inmobiliaria, la explotación y exportación de bienes primarios, agrocombustibles -soja, caña de 
azúcar, maíz, palmera-, hidrocarburos -gas y petróleo- y metales y minerales -oro, plata, cobre, bauxita-. Todo lo cual pone en juego intereses y luchas de poder por el territorio que expresan territorialidades en disputa

En América Latina (AL), y especialmente en el Cono Sur latinoamericano, este proceso está asociado con la dominación territorial de los commodities. En los hechos, su promoción y difusión invade la vida cotidiana de toda la población, aunque bajo modalidades y formas que ocultan sus consecuencias negativas en relación a lo social, económico, político e institucional.

Los medios masivos de comunicación, la prensa, el discurso político, las políticas públicas, la percepción social dominante, consideran y difunden que los commodities son la oportunidad y la solución de buena parte de los que se definen como problemas de desarrollo de AL, cuando en realidad son todo lo contrario si no se interviene políticamente en los mismos y se controla y dirige su proceso de acumulación.

En este contexto, AL aparece como un continente privilegiado porque sus recursos naturales corresponden a este nuevo designio de acumulación capitalista, en el que la principal condición es tan sólo respetar y seguir las nuevas reglas que dominan a escala planetaria (en relación a lo productivo, tecnológico, comercial, institucional).

Sin embargo, otro es el panorama cuando observamos que el hambre y la no sustentabilidad energética presentes en el escenario mundial devienen del modelo capitalista de crecimiento y acumulación, cuyos usos del espacio y sus recursos cada vez más intensivos, regresivos y degradantes son una resultante de la concentración de la riqueza, con sus repetidas crisis de sobreacumulación y generación de desigualdades cada vez más agudas.

Desde el nuevo milenio, en AL en particular (pero también en Asia y África) la valoración del capital se genera a través de formas cada vez más intensivas de explotación y exportación de bienes primarios, como los cultivos asociados con los agrocombustibles -soja, caña de azúcar, maíz, palmera- los hidrocarburos gas y petróleo- y los metales y minerales -oro, plata, cobre, bauxita-. En todos estos casos los precios se fijan internacionalmente y suelen tener un sostenido crecimiento que deriva en concomitantes crisis de alimentación con sus secuelas de hambre, y que paralela o posteriormente devienen en crisis financieras, energéticas, económicas, con recesiones generalizadas.

\section{- La seguridad y la soberanía alimentaria peligra frente al avance del extractivismo y la reprimarización de la economía}

Identificar y desenmascarar a los principales responsables de los procesos que conllevan al aumento del hambre, de la desnutrición y que atentan contra la vida misma de la población mundial es un requisito en el proceso de generación; un desarrollo que se considere sustentable y compatible con la democracia.

Paulo Tavares (2013) sostiene que el extractivismo y la reprimarización expresan "una fiebre global por la tierra, por la minería y por los recursos naturales en general”.

En las más de 55 millones de hectáreas cultivadas con soja del Cono Sur en 2014, quienes controlan y operan estos procesos lo hacen con similares modalidades. En la mayor parte de esta superficie predomina el monocultivo de soja transgénica, se fumiga con glifosato y se deforesta para ampliar la superficie cultivable.

De todos modos, las transformaciones territoriales asociadas con la sojización trascienden al Cono Sur latinoamericano; aparecen en otras geografías y territorios y no sólo en los vinculados directamente con la producción de soja. 
Lo que se presenta como un boom productivo en el agro oculta que, conjuntamente, conduce a poner en riesgo la salud de la población, la seguridad y la soberanía alimentaria de la población mundial.

El aumento de la producción de biocombustibles (consecuencia de las crisis energéticas y de la volatilidad del precio del petróleo) y el mayor consumo de carne en el mundo (asociado con el aumento de sectores medios y, especialmente, con la promoción de este consumo en China) ha aumentado la producción de ganado alimentado con granos (feedlot).

Ambos tipos productivos (biocombustible y ganado) compiten y desplazan a la producción de granos mundialmente reconocida y utilizada como base de la alimentación humana.

Por ello, esta mecánica de acumulación opera contra la seguridad y soberanía alimentaria y pone en riesgo el futuro de las mayorías más vulnerables de la población mundial, para quienes la alimentación con granos es central. Por lo tanto, la menor producción por avance de otras actividades agropecuarias, conducirá a su escasez y encarecimiento. Simultáneamente, la expansión de biocombustibles y carnes avanza en beneficio de los sectores de mayor poder adquisitivo que pueden acceder a esos consumos, y de los intereses de las grandes corporaciones estadounidenses (Tyson y Smithfield) que son las que lideran la expansión de las industrias de producción de carne en China.

Lo que se está haciendo es repetir el modelo de producción industrial y de consumo de carne de los países del norte en el sur y en China, sin importar sus particularidades territoriales, ni sus consecuencias sociales y ambientales. Debe mencionarse que en este proceso participa el Banco Mundial (BM) financiando la expansión de las instalaciones para el engorde de ganado en China. Este apoyo al mayor consumo de carne en este país es una política que contradice los lineamientos del propio BM vinculados con la protección ambiental.

Los grupos que lideran y conducen el extractivismo y la reprimarización de la economía de Sudamérica pueden ser identificados y deberían ser denunciados por la sucesión de muertes por contaminación y asesinatos, cuyas causas se acallan para proteger sus intereses. Los responsables de estos procesos contra la vida y la alimentación humana se encuentran entre los propietarios, accionistas y los principales jefesejecutivos (CEO's) de las mayores y más concentradas empresas biotecnológicas y del agribusiness. Desde Monsanto a las corporaciones biotecnológicas (como Syngenta, Bayer) siguiendo con los terratenientes y pooles de siembra que gestionan millones de hectáreas (los Grobo, CRESUD, El Tejar, Maggi), con Cargill, ADM y Bunge que transportan los granos al otro lado del mundo, llegamos, por supuesto, a los gobiernos (y sus principales referentes en el ejecutivo, legislativo y judicial) de cada uno de los países que apoyan de manera entusiasta este modelo.

\section{- La disputa por la tierra se profundiza hasta poner en riesgo la vida de la población campesina e indígena afectada}

El modelo extractivista y de reprimarización de las economías latinoamericanas y sus escenarios territoriales, opresivos y desbastadores, ponen en permanente riesgo la vida de las familias campesinas y rurales tras la disputa por la tierra y la contaminación ambiental

La expansión de los agronegocios y en particular la reprimarización de la economía, asociada principalmente con la sojización, conlleva a profundas transformaciones territoriales a través del despojo de los recursos, el avasallamiento y persecución de la población local, y la judicialización de la protesta social 
Son modos de sometimiento, cada vez más extendidos que, además, cuentan con avales institucionales en beneficio de poderosos intereses locales y extralocales (económicos, financieros, políticos, judiciales).

Comunidades originarias, pequeños productores, campesinos, agricultura familiar (AF) en función de sus particularidades -territoriales, productivas, tecnológicas sociales- se enfrentan al hambre, la migración forzada, la difusión de enfermedades, la contaminación del agua, las fumigaciones con agrotóxicos, la destrucción de puestos y fuentes de trabajo, la deforestación, la depredación de suelos, la pérdida de la biodiversidad.

Pero además, vale señalar que en distintos lugares del Cono Sur oponerse a los agronegocios ha costado vidas humanas.

En Argentina, en sólo dos años fueron asesinados cuatro militantes por la defensa del territorio. El 12 de octubre de 2009 ejecutaron en Tucumán al diaguita Javier Chocobar; el 13 de marzo de 2010 falleció de un paro cardíaco frente a una topadora la campesina santiagueña Sandra "Ely” Juárez; el 23 de noviembre de 2010 fue asesinado en un corte de ruta el qom de Formosa Roberto López; el 16 de noviembre de 2011 se sumó a esta lista Cristian Ferreyra, un caso lamentablemente emblemático en relación a los desmontes. Este joven de 23 años fue baleado por dos hombres cuando intentó resistir un desalojo en el campo donde vivió toda su vida, en el paraje San Antonio, al norte de Santiago del Estero. (Página 12, 18-11-2011). En ningún caso están detenidos los autores materiales ni intelectuales de los crímenes -no fueron procesados o bien fueron sobreseídos-. Esto indica connivencia entre las autoridades locales, policiales y judiciales y los sectores de poder local y extralocal interesados en desalojar a las familias de campesinos que viven en los campos en conflicto con potencialidades para la producción sojera, la forestación u otras alternativas.

Similares situaciones se repiten en muchos otros ámbitos de AL como, por ejemplo, sucede en Paraguay $\underline{9}$. En este escenario ocurrió la matanza de Curuguaty (11 campesinos y 6 policías muertos el 15-6-2012) que llevó a la destitución del gobierno democrático del presidente Lugo y a una ola represiva que terminó con la vida de 3 dirigentes de organizaciones campesinas.

En los hechos, se trata de una lucha muy desigual en la que sectores empresarios violan el cumplimiento de las leyes y atentan contra los derechos consagrados en la constitución y en diversas leyes, de modos que incluso llegan hasta el asesinato. Claramente todo indica complicidad del estado, en tanto son hechos que no se investigan adecuadamente y con celeridad, y cuyos autores materiales e intelectuales no son debidamente procesados, ni encarcelados.

\section{- Deforestación y desertificación y sus múltiples impactos desde el campo sociopolítico al ambiental}

Los bosques naturales amenazados por la sojización, con la consecuente desertificación y pérdida de biodiversidad, son fuente de conflictos con la población afectada.

La sojización avanza espacialmente deforestando y limitando la diversidad biológica de numerosos territorios.

En Argentina la situación forestal está en emergencia desde hace unos 15 años, porque se perdió el 70 por ciento de los bosques nativos originales. Y el ritmo de deforestación se torna cada vez más acelerado. Entre 1998-2002 se deforestaba en promedio 230.000 hectáreas/año, entre 2002-2006, 330.000 hectáreas/año de bosques nativos (Secretaría de Medio Ambiente y Desarrollo Sustentable de la Nación; 2012, pp. 95, 97). 
En el 2011, año internacional de los bosques, un informe de Greenpeace sostenía que en los 10 años anteriores se habían perdido 2,5 millones de hectáreas a expensas, fundamentalmente, de la soja transgénica y posteriormente de la ganadería $\underline{10}$. Un informe anterior de la Secretaría de Ambiente y Desarrollo Sustentable de la Nación (2004, p. 4) indicaba que la superficie en hectáreas de Bosque Nativo era la siguiente: 1937: 37.535 .308 ha; 1987: 35.180 .000 ha; 1998: 33.190 .442 ha. Esto muestra una constante pérdida de superficie y la existencia de una aceleración de este proceso en las últimas décadas.

Un ejemplo representativo que condensa varias de las consecuencias sociales, económicas, políticas e institucionales negativas de estos procesos de deforestación es el "caso Pizarro" en Salta, Argentina, representativo de los conflictos emergentes entre intereses fuertemente confrontados en torno a la deforestación, en especial en relación a la prolongada y profunda resistencia social a la deforestación y al accionar del poder hegemónico, cuyos mecanismos dilatorios y de manipulación y negación de las leyes y de los derechos institucionalizados resultan más que evidentes (Bianchi y Couto, 2013).

Se trata de un conflicto que se inició con la promulgación de la ley provincial 7274 de 2003 que desafectó dos lotes fiscales (el 32 de 5.298 ha y el 33 de 20.028 ha) de la categoría de área natural protegida para destinarlos a la producción sojera. Esta ley que fuera aprobada por 2/3 de los senadores y diputados provinciales es un acuerdo espurio entre sectores del poder político y económico provincial. El mismo derivó en una extensa y prolongada crisis política y condujo a la movilización de organizaciones sociales, ambientalistas e indígenas de alcance nacional e internacional.

Precisamente, el conflicto y la movilización fueron un importante antecedente en el dictado de la Ley de Bosques 26.331 de fines 2007, lograda luego de muchas tratativas y dirigida a controlar los desmontes a partir de la instrumentación de pautas de Ordenamiento Territorial de los Bosques Nativos (OTBN) en todo el país. Sin embargo, la restricción para desmontar, excepto previo cumplimiento del OTBN, fue rápidamente subvertida. Del mismo modo que en buena parte de las zonas provinciales afectadas por la restricción de desmontes se recurrió a variados procedimientos que permitieron soslayar el cumplimiento de esta ley, y acelerar la venta y deforestación de las tierras antes de su sanción y promulgación, o antes de su puesta en marcha efectiva.

\section{Conclusión}

La expansión de los commodities está asociada a la consolidación de un modelo de acumulación cada vez más concentrado y regresivo, que se traduce en una cada vez mayor y creciente desigualdad, cuya manifestación más notoria es la población excluida y subordinada de los procesos que, eufemísticamente, denominamos de “desarrollo".

De este modo, mientras la concentración económica beneficia a una minoría privilegiada se avasallan los derechos de los sectores más desprotegidos y precarizados del ámbito rural y urbano.

Este modelo impuesto a partir de la profundización de las prácticas neoliberales da cuenta de dos problemáticas interrelacionadas que consideramos centrales:

- Una, que la cuestión de la tierra y de los recursos ha sido, y sigue siendo, central en la disputa de poder del modelo de acumulación capitalista por desposesión de la actual etapa (conocida como de financiarización) de la economía.

- Y la otra, que la promoción, ampliación y difusión de estas producciones, de consecuencias regresivas -en el campo social, político, institucional y ambiental- se sostienen por la construcción 
de un discurso hegemónico que afirma y publicita que la economía de la mayoría de los países del Cono Sur depende y necesita de estas actividades para garantizar su crecimiento y bienestar. Este discurso construido para las grandes mayorías se constituye en discurso de verdad, en tanto se acepta generalizadamente y no se somete a discusión. De este modo se justifica, sostiene y consolida un modelo económico-productivo dominante, en el que las organizaciones y sectores sociales que se oponen son permanentemente cuestionados, judicializados y perseguidos con diferentes métodos, cuando no reprimidos, encarcelados y asesinados.

Convivir, oponerse y enfrentarse al poder hegemónico y a sus variadas expresiones -económicas, políticas, financieras, culturales- es una tarea enorme, que abarca diversos e infinitos frentes. Entre todos ellos, entendemos que el más complejo es el que se vincula con el discurso que naturaliza hechos y realidades como los que aquí nos ocupan -vinculados con la expansión de los commodities- y que los plantea como resultantes de un devenir natural y necesario para el bien de todos y del desarrollo de la nación en cuestión.

Se trata de un discurso de poder, una construcción de verdad: la verdad del poder hegemónico que se conforma ocultando, desinformando, desvalorizando toda evidencia sobre los efectos negativos que estos procesos productivos conllevan.

Es este contexto cultural hegemónico el que logra que las actuales consecuencias de la producción del territorio y de valorización del capital (ligadas al extractivismo y a la reprimarización de las economías sudamericanas) se tornen lejanas e incomprensibles para la gran mayoría de la población, que desconoce, minimiza o desestima la profundización de la desigualdad y la marginación social, las consecuencias ambientales, políticas, económicas, sociales e institucionales -presentes y futuras- del avance de los commodities, la persecución, la opresión y la discriminación de los numerosos actores involucrados.

Para comprender más profunda e íntimamente estos procesos deberíamos tener presente, cual dogma, que "las formas espaciales son productos históricos, que el espacio producido es un resultado de la acción humana sobre la superficie terrestre que expresa, a cada momento, las relaciones sociales que le dieron origen” (Moraes, 2005, p. 15)

\section{Notas}

1 Este trabajo se enmarca dentro de la temática de los proyectos UBACyT 2016 (010031); PIP Conicet 2012 (0273). PICT FONCyT-Agencia 2015 (0653).

$\underline{2}$ La fecha de cierre del período tiene que ver con el momento en que en los distintos países se adoptan los Consensos de Washington y comienzan a aplicarse las medidas del modelo neoliberal conduciendo al desplazamiento del modelo keynesiano.

3 La Alianza para el Progreso fue un programa por 10 años, de 20.000 millones de dólares financiados por organismos multilaterales (como el BID -Banco Interamericano de Desarrollo), cuyo objetivo explícito fue mejorar la vida de los habitantes de AL. Sin embargo, su finalidad era contrarrestar la atracción y los impactos sociopolíticos de la revolución cubana en AL. En la Conferencia de Punta del Este participaron todos los países miembros de la Organización de Estados Americanos (OEA), incluida Cuba (representada por Ernesto "Che" Guevara).

4 La diferencia entre países respecto a los años que delimitan los períodos se debe a que el modelo neoliberal no se inició en el mismo momento en toda AL y tampoco se aplicó de la misma forma. 
$\underline{5}$ El neoliberalismo se postulaba como el único y más adecuado modelo económico para enfrentar la crisis socioeconómica y política existente. $\mathrm{Y}$ entre sus principales postulados de entonces figuraba la no participación activa del Estado en la actividad económica, y se hacía un culto del laissez faire y sus ventajas competitivas en sentido amplio, mientras se ocultaban o ignoraban sus efectos regresivos para la mayoría de la población en el campo social, político y económico.

$\underline{6}$ En los países donde golpes militares garantizaron la aplicación del modelo neoliberal es necesario comprender que no fueron sólo militares los responsables directos, sino que se gestó un acuerdo cívicomilitar-eclesiástico que logró la complicidad que requería el ocultamiento del genocidio realizado.

$\underline{7}$ Un ejemplo actual lo encontramos en el dominante proceso de reprimarización de las economías del Cono Sur de AL controlado directa o indirectamente por grandes corporaciones multinacionales (Monsanto, Syngenta, Bayer, Cresud, Cargill, ADM, Maggi, Bunge, entre otras). Se trata de procesos que conducen a deforestación, contaminación, expulsión y persecución de pobladores campesinos, judicialización de la protesta social, y que consecuentemente condicionan la soberanía nacional por la pérdida de la autonomía en la gestión política, económica y científica de los países.

8 Como señalamos arriba, entre 1960 y 1980 el territorio también estuvo presente en las políticas de desarrollo, pero entonces en su versión de “desarrollo regional”.

9 “el 80\% de la tierra cultivable... está en manos del 2\% de los propietarios, según cifras oficiales”

10 Había entonces 31 millones de hectáreas de bosque nativo.

\section{Bibliografía}

Bianchi, S. y Couto, M. (2013). El caso ‘Pizarro’ (Salta): movilización y poder. En M. Manzanal y M. Ponce (Org.). La desigualdad ¿del desarrollo? Controversias y disyuntivas del desarrollo rural en el norte argentino (pp.213-232). Buenos Aires: CICCUS.

Credit Suisse (2015). Global Wealth Databook 2015

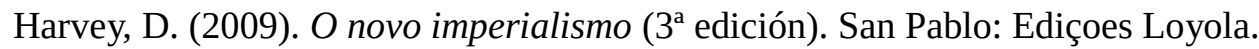

Moraes, A. (2005). Ideologías Geográficas. Espaço, cultura e Política no Brasil (5ª edición). San Pablo: Annablume Editora.

Oxfam (2016). Una economía al servicio del 1\% (www.oxfam.org)

Secretaría de Ambiente y Desarrollo Sustentable de la Nación (2004). Informe sobre deforestación en Argentina. Dirección de Bosques, Unidad de Manejo del Sistema de Evaluación Forestal, Buenos Aires, Argentina.

Secretaria de Ambiente y Desarrollo Sustentable de la Nación (2012). Informe sobre el estado del ambiente 2012. Buenos Aires: Jefatura de Gabinete Presidencia de la Nación Argentina.

Tavares, P (2013). La naturaleza va a la Justicia, entrevista a Paula Tavares por Timo Berger, 19-6-2013. http://www.iade.org.ar/noticias/la-naturaleza-va-la-justicia

Sassen, S. (2007). Una sociología de la globalización. Buenos Aires: Katz Editores. 